\title{
Sexual and Emotional Aspects are Distinct Components of Infidelity and Unique Predictors of Anticipated Distress
}

\author{
Daniel J. Kruger • Maryanne L. Fisher • Carey J. Fitzgerald • \\ Justin R. Garcia • Glenn Geher • Amanda E. Guitar
}

Published online: 16 January 2015

(C) Springer International Publishing 2015

\begin{abstract}
Although there has been a tremendous amount of research attention on differences in reactions to sexual infidelity and emotional infidelity, there is a lack of information available as to how the two constructs overlap with respect to actual behavior, how expectations for distress vary by behavior, and how sexual and emotional content influence expectations for distress. In order to address this issue, we asked participants to rate 50 behaviors on the extent to which each would constitute sexual infidelity and, separately, emotional infidelity. Participants also rated the degree to which they would be upset if their partner performed the behavior, which enabled us to determine the relationship between views of sexual infidelity, emotional infidelity, and anticipated distress. As predicted, ratings of sexual infidelity and emotional infidelity for the 50 behaviors were largely independent. In agreement with past research, ratings of emotional infidelity were stronger predictors of distress for women than for men, whereas ratings of sexual infidelity were overall stronger predictors
\end{abstract}

D. J. Kruger $(\bowtie)$

University of Michigan, 1420 Washington Heights, Ann

Arbor, MI 48109-2029, USA

e-mail: kruger@umich.edu

M. L. Fisher

Saint Mary’s University, Halifax, NS, Canada

C. J. Fitzgerald

University of South Carolina - Beaufort, Beaufort, SC, USA

J. R. Garcia

Indiana University Bloomington, Bloomington, IN, USA

G. Geher

State University of New York at New Paltz, New Paltz, NY, USA

A. E. Guitar

State University of New York at Binghamton, Binghamton, NY, USA of distress for men than for women. Furthermore, ratings of sexual infidelity were overall stronger predictors of distress than ratings of emotional infidelity for both women and men. However, ratings of sexual infidelity were overall stronger predictors of ratings of emotional infidelity for men than for women. The results generally support predictions derived from an evolutionary perspective, elaborating upon the existing understanding of sex differences in anticipated reactions to infidelity.

Keywords Sex differences · Infidelity · Distress · Evolutionary psychology

There is a considerable body of literature on infidelity within romantic relationships (for a review, see Tsapelas et al. 2010). Several recent articles have been published on a wide variety of different aspects of unfaithfulness: sex differences in emotional responses to heterosexual and homosexual infidelity (Dural et al. 2014), responses to infidelity involving kin (Kostic and Yadon 2014), conceptualization of opposite-sex and same-sex infidelity within the context of a heterosexual marriage (Clarke et al. 2014), and endocrinological and behavioral responses to rivals after cognitive priming about infidelity (Maner et al. 2014), among other topics. Taken together, there now exists a substantial academic literature on the psychological effects of infidelity.

Many infidelity studies are based on the now classic forced-choice paradigm developed over two decades ago by Buss et al. (1992), in which individuals are asked whether they would be more distressed (e.g., upset, jealous) if their partner had sexual intercourse with another person (i.e., sexual infidelity) or if their partner formed a deep emotional bond with another person (i.e., emotional infidelity). Across studies, women generally anticipate being more upset by imagined 
emotional infidelity than men, and men generally anticipate being more upset by imagined sexual infidelity than women (for a review and meta-analysis, see Sagarin et al. 2012). We note that the original study's predictions were previously replicated, though inconsistently, with continuous measures (e.g., DeSteno and Salovey 1996; Edlund and Sagarin 2009; Wiederman and Allgeier 1993) and that these patterns may be limited to heterosexuals (Frederick and Fales 2014). Yet, these sex differences are robust to challenges depicting them as an artifact of attachment style, sex-roles, sociosexual orientation, interpersonal trust, culture of honor beliefs, and beliefs about the implications of infidelity (Brase et al. 2014).

Research on infidelity consistently operationalizes sexual infidelity and emotional infidelity as separate conditions. In reality, human extra-pair sexual behavior ranges from flirting to sexual intercourse to long-term romantic relationships, with frequency inversely related to intensity (Buunk 1980). There is also a range of behaviors related to one's emotional connection and level of material support. For example, researchers (Kruger et al. 2013; Mattingly et al. 2010) recently investigated the degree to which specific behaviors were considered infidelity, finding that perceptions of cheating fall along a continuum. Sexual behaviors were thought to be most indicative of infidelity, whereas behaviors involving financial support were considered less indicative of infidelity. Behaviors associated with being involved in a romantic relationship (e.g., accompanying to a formal event, staying in the same hotel room, spending lots of time together) were in the middle of this continuum (Kruger et al. 2013).

In a study of U.S. undergraduates at three colleges, the majority of women and men reported that they believed that emotional infidelity could occur without sexual infidelity, and that sexual infidelity could occur without emotional infidelity (Guitar et al. under review). In contrast, another study involving U.S. undergraduate students as participants found women were more likely to believe that their male partners could engage in sexual intercourse without emotional attachment, whereas men were more likely to believe that their female partners could not engage in sexual intercourse without emotional attachment (Harris \& Christenfeld, 1996). Although Guitar et al.'s (under review) more recent study found that most individuals of both sexes believed the two forms of infidelity are distinct, Harris and Christenfeld (1996) found this to be the case only for women's views of male psychology. Therefore, it remains unknown whether the different findings are due to methodological differences in reporting one's own beliefs regarding conspecifics and degree of cross-sex mind reading, or attributable to other causes. In either case, we note that these were relative differences, rather than strong differentiations between emotional infidelity and sexual infidelity, as all mean ratings were near the midpoint of the bipolar scale. Moreover, both of these studies used basic general questions.
Despite research often operationalizing distinct infidelity conditions, previous work has not systematically examined the degree to which specific behaviors are considered sexual infidelity and emotional infidelity, how expectations for distress vary by such behaviors, or how the degree of sexual and emotional content influences expectations for distress. Therefore, the purpose of the current project was to extend the literature on infidelity by examining these three aspects. We expected to replicate the robust findings of sex difference in reactions to infidelity with a more nuanced methodology.

In an evolutionary perspective, the context of most human sexual behavior and reproduction appears to be long-term sociosexual pair-bonds (Fisher 1992; Gray and Garcia 2013). However, given sex differences in minimal parental investment and potential maximum reproductive rate, men and women have evolved differences in tendencies toward sexual fidelity within their pair-bond relationships. Given men's lack of paternity certainty, the potential costs of a mate's sexual infidelity loom larger for men than women. Given women's evolutionary and historical reliance on men's protection and resource acquisition for themselves and any dependent children, the potential costs of mate's emotional infidelity and diversion (or desertion) of investment looms larger for women than men.

Evidence shows that paternal investment by means of provisioning food and care lowers infant and child mortality, and may improve the physical health of children (e.g., Hill and Hurtado 1996; see Geary 2005 for a review). Thus, we predicted that emotional infidelity would be a stronger predictor of distress for women than for men (prediction 1). Geary (2005) reviewed the link between paternal investment and paternity certainty, arguing that in humans, it is not always necessary for men to invest in children to ensure their survival. When men have a high degree of paternity certainty, which enables them to invest their care in children with some confidence that they are genetic relatives, men tend to do so, particularly if such care improves child survivability. Consequently, given paternal uncertainty and the considerable costs of cuckoldry to a man's reproductive success, we predict that sexual infidelity would be a stronger predictor of distress for men than for women (prediction 2). These predictions are consistent with Buss et al.'s (1992) original hypotheses.

We also examine the relative predictive strength for each type of infidelity within-sex, separately for women and men. This stronger version of effects is considered to be confirmatory evidence by critics of the original theory (e.g., Buller 2005), however Edlund and Sagarin (2009) argue that this view is mistaken and recommend the less stringent criterion on an interaction effect over separate predictions of within-sex differences. We predict that women's distress will be more strongly influenced by emotional infidelity than by sexual infidelity (prediction 3). Likewise, we predict that men's distress will be more strongly influenced by sexual infidelity than 
by emotional infidelity (prediction 4). In addition, we attempt to find additional evidence for Harris and Christenfeld's (1996) claim that women see men as more likely to separate sexual from emotional aspects of infidelity, compared to men's expectations for women. If this is the case, ratings of emotional infidelity will be more strongly associated with ratings of sexual infidelity for male participants than for female participants (prediction 5).

\section{Method}

Participants and Procedure

Ethnically diverse undergraduate students $(N=379 ; 71 \%$ female, $29 \%$ male; $M$ age $=21$ years, $\mathrm{SD}$ age $=5$ years) from two public Mid-West universities and one public Northeast university in the USA completed anonymous on-line surveys at their convenience. Data from one participant who identified as transgendered were removed, due to the sex-specific nature of the surveys. Participants were asked to complete the surveys in locations where their responses would be private.

Participants were asked to imagine discovering that their long-term relationship partner performed a behavior with someone else who is the same sex as the participant. Participants then read a list of 50 behaviors, elaborated from Kruger et al. (2013), with additional behaviors specified by the current authors. These items included sexually interactive behaviors, erotic behaviors without physical contact, behaviors suggesting a romantic relationship, behaviors indicating emotional or financial support, and casual social interactions (see Table 4 in Appendix). Participants rated the items, first on the extent to which they would be upset by each behavior if it were performed by their own partner, then on the extent to which the behavior would constitute sexual infidelity and emotional infidelity. Participants, therefore, rated each behavior three times using a sliding scale ranging from 0 to $100 \%$ and initially set at $50 \%$. Selected values were displayed to participants, and each scale could be modified until participants advanced to the next page. Ratings for sexual infidelity and emotional infidelity were completed on separate survey pages in randomized order. The survey program displayed items within each set in randomized orders.

\section{Analyses}

We examined ratings of the 50 behaviors with a multi-level model, with responses nested within individuals. We included participant age and sex (female/male) as level 2 predictors of ratings of how upsetting the behaviors would be and included ratings of sexual infidelity and emotional infidelity as level 1 predictors of how upsetting each behavior would be. We included interaction terms between participant sex and ratings of sexual infidelity and emotional infidelity to assess predictions 1 and 2 (see model in Fig. 1). We then split the data by sex and ran separate multi-level analyses to assess predictions 3 and 4 . We used the full dataset with sexual infidelity as the outcome variable to test prediction 5 . We also aggregated responses separately across female and male participants and examined the correspondence between ratings of sexual infidelity and emotional infidelity, with an interaction term for participant sex and emotional infidelity. We included participant age as a level 2 predictor in all models.

\section{Results}

Results supported predictions 1 and 2, as ratings of emotional infidelity were overall stronger predictors of distress for women than for men, and ratings of sexual infidelity were overall stronger predictors of distress for men than for women (see Table 1). Ratings of sexual infidelity were overall stronger predictors of distress than ratings of emotional infidelity for both women and men, supporting prediction 4 but refuting prediction 3 (see Table 2). Emotional infidelity ratings were a stronger predictor of sexual infidelity ratings for male participants than for female participants, supporting prediction 5 (see Table 3).

Men and women differed in how they perceived the distinctiveness of the two forms of infidelity. Aggregate ratings of sexual infidelity and emotional infidelity by men shared $30 \%$ variance, $r_{(50)}=0.551, p<0.001$, however ratings by women only shared $1 \%$ variance, $r_{(50)}=0.114, p=0.432$. Moreover, younger women tended to predict greater distress than older women, whereas there were no effects for age in men (see Table 2).

There was also a small tendency for women to be more upset than men on eight items that ranged across the various domains. These items were as follows: forming a deep emotional bond, accompanying to a formal event, intentionally having a child together, holding hands, e-mailing or texting erotic written messages, going on vacation together, penile-

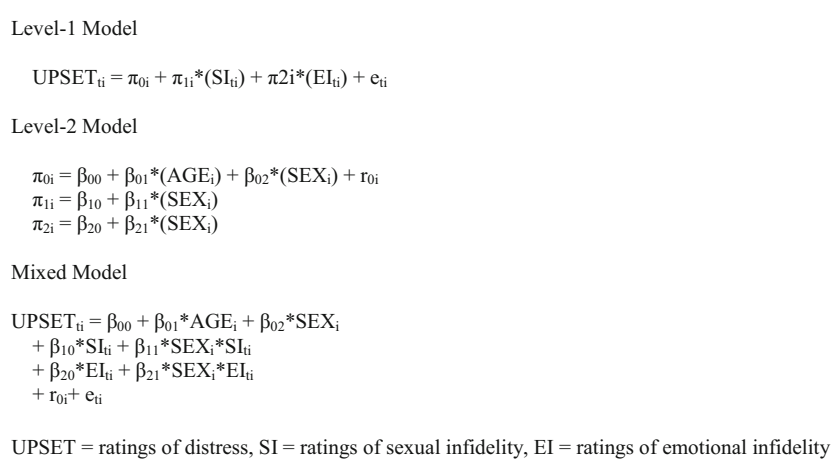

Fig. 1 Multilevel model predicting ratings of distress for each behavior 
Table 1 Full multilevel model results

\begin{tabular}{lllllr}
\hline Fixed effect & Coefficient & SE & $t$ ratio & $d . f$. & $p$ value \\
\hline For INTRCPT1, $\pi_{0}$ & & & & & \\
$\quad$ INTRCPT2, $\beta_{00}$ & 36.712859 & 4.500740 & 8.157 & 374 & $<0.001$ \\
AGE, $\beta_{01}$ & -0.301425 & 0.149248 & -2.020 & 374 & 0.044 \\
$\quad$ SEX, $\beta_{02}$ & 3.348936 & 1.866572 & 1.794 & 374 & 0.074 \\
For SI slope, $\pi_{1}$ & & & & & \\
$\quad$ INTRCPT2, $\beta_{10}$ & 0.526956 & 0.018891 & 27.894 & 18469 & $<0.001$ \\
$\quad$ SEX, $\beta_{11}$ & -0.033701 & 0.010457 & -3.223 & 18469 & 0.001 \\
For EI slope, $\pi_{2}$ & & & & & \\
$\quad$ INTRCPT2, $\beta_{20}$ & 0.138298 & 0.024006 & 5.761 & 18469 & $<0.001$ \\
SEX, $\beta_{21}$ & 0.030073 & 0.013215 & 2.276 & 18469 & 0.023 \\
\hline
\end{tabular}

$1=$ male, $2=$ female

vaginal intercourse, and e-mailing or texting erotic pictures of themselves. Effect sizes ranged from 0.22 to 0.29 (see Table 4 in Appendix).

\section{Discussion}

There has been considerable research attention devoted to contrasts of sexual infidelity and emotional infidelity. Despite this, however, prior work has not addressed how actual behaviors are understood by each sex as being indicative of sexual

Table 2 Multilevel results by participant sex

\begin{tabular}{llllll}
\hline Fixed effect & Coefficient & SE & $t$ ratio & $d . f$. & $p$ value \\
\hline Women & & & & & \\
For INTRCPT1, $\pi_{0}$ & & & & & \\
$\quad$ INTRCPT2, $\beta_{00}$ & 47.225054 & 4.457182 & 10.595 & 264 & $<0.001$ \\
$\quad$ AGE, $\beta_{01}$ & -0.482024 & 0.205489 & -2.346 & 264 & 0.020 \\
For SI slope, $\pi_{1}$ & & & & & \\
$\quad$ INTRCPT2, $\beta_{10}$ & 0.459566 & 0.005220 & 88.035 & 13032 & $<0.001$ \\
For EI slope, $\pi_{2}$ & & & & & \\
$\quad$ INTRCPT2, $\beta_{20}$ & 0.198280 & 0.006436 & 30.806 & 13032 & $<0.001$ \\
Men & & & & & \\
For INTRCPT1, $\pi_{0}$ & & & & & \\
$\quad$ INTRCPT2, $\beta_{00}$ & 62.799756 & 6.547310 & 9.592 & 109 & $<0.001$ \\
$\quad$ AGE, $\beta_{01}$ & 0.000761 & 0.301247 & 0.003 & 109 & 0.998 \\
For SI slope, $\pi_{1}$ & & & & & \\
$\quad$ INTRCPT2, $\beta_{10}$ & 0.493308 & 0.008973 & 54.978 & 5437 & $<0.001$ \\
For EI slope, $\pi_{2}$ & & & & & \\
$\quad$ INTRCPT2, $\beta_{20}$ & 0.166284 & 0.011554 & 14.392 & 5437 & $<0.001$ \\
\hline
\end{tabular}

Table 3 Prediction of sexual infidelity ratings from emotional infidelity ratings

\begin{tabular}{lccrlr}
\hline Fixed effect & Coefficient & SE & $t$ ratio & d.f. & $p$ value \\
\hline For INTRCPT1, $\pi_{0}$ & & & & & \\
$\quad$ INTRCPT2, $\beta_{00}$ & 20.30 & 4.78 & 4.24 & 374 & $<0.001$ \\
AGE, $\beta_{01}$ & -0.01 & 0.15 & -0.10 & 374 & 0.924 \\
$\quad$ SEX, $\beta_{02}$ & 7.25 & 2.03 & 3.57 & 374 & $<0.001$ \\
For EI slope, $\pi_{1}$ & & & & & \\
$\quad$ INTRCPT2, $\beta_{10}$ & 0.50 & 0.04 & 13.56 & 18845 & $<0.001$ \\
SEX, $\beta_{11}$ & -0.18 & 0.02 & -8.80 & 18845 & $<0.001$ \\
\hline
\end{tabular}

$1=$ male, $2=$ female

infidelity and emotional infidelity. Likewise, there has been a dearth of attention on the imagined distress resulting from actual behaviors involved in an infidelity. To address these gaps in the literature, we incorporate a wide range of behavioral domains and address individual differences in perceptions of infidelity.

As expected, we replicated the patterns found using forced choice methods and simple item content, using a more detailed and behaviorally informed methodology. We found support for the prediction that emotional infidelity ratings would be stronger predictors of imagined distress for women than for men, given that prior research has established the importance women tend to place on emotional fidelity within romantic relationships. Also informed by past research findings, we predicted that men would place more importance on sexual fidelity within their relationships compared to women. We confirm this, as our findings supported our second prediction in that ratings of sexual infidelity were overall stronger predictors of imagined distress for men than for women.

Ratings of sexual infidelity were overall stronger predictors of distress than ratings of emotional infidelity for both women and men. Although this pattern confirms the prediction for men (prediction 4), it refutes the prediction for women (prediction 3). However, this is consistent with Fisher et al.'s (2008) finding that both men and women believed their opposite-sex partners would have a more difficult time forgiving sexual infidelity than emotional infidelity. This is also consistent with the cross-cultural literature, wherein both men and women desire sexual exclusivity from their romantic partners and engage in mate-guarding behaviors to maintain sexual fidelity (Jankowiak et al. 2002). It is possible that behavioral violations of a pair-bond are considered to be more severe than mental violations, similar to the idea that "doing" an act is more meaningful than thinking about another person or a potential action. We note that the predictions presented here address interpretations found in the infidelity literature 
(Buller 2005), yet may not be appropriate criteria for evaluating the original hypothesis (Edlund and Sagarin 2009).

Harris and Christenfeld (1996) claimed that women view men as more able to separate sexual and emotional aspects of infidelity, compared to men's views of women. Convergent with this claim, we find that the sexes differed in how they perceived the distinctiveness of the two forms of infidelity. Men's aggregate ratings of sexual infidelity and emotional infidelity in behaviors performed by female partners showed a far higher degree of shared variance (30\%) than women's ratings of behaviors performed by male partners $(1 \%)$. This pattern was consistent with the multilevel model, where emotional infidelity ratings were a stronger predictor of sexual infidelity ratings for male participants than they were for female participants.

Younger women tended to predict greater distress than older women; there were no effects for age in men. Interestingly, some past research (e.g., Green and Sabini 2006) did not find an age effect. In contrast, records using actual experiences with sexual infidelity (Atkins et al. 2001) seem to show an interaction between the predictor variables of sex and age such that men 55-65 years old were the most likely to report having had an infidelity; among only women, those in the age range of 40-45 reported the highest rates of infidelity. For those 45 and under, there was no significant sex difference (Atkins et al. 2001). In the current study, although the differences were not systematic, women tended to predict greater imagined distress for items related to both male and female mate value and roles in reproduction (e.g., giving \$500, e-mailing or texting erotic pictures of themselves). It is possible that women anticipate being more emotionally reactive to such relationship slights, though we do not know whether this difference would occur in actual instances. However, men are more likely than women to initiate divorce proceedings because of infidelity (Buckle et al. 1995), though the types of behaviors used as grounds for separation are those rated most severely in our study.

One strength of the current study is that it addresses issues pertaining to forced-choice survey methods, which were the foundation upon which this area developed (e.g., Buss et al. 1992). For example, Fenigstein and Peltz (2002) found that although both women and men believe each infidelity may occur independently, participants felt sex-only infidelity was more plausible for men and emotion-only infidelity more plausible for women. The authors concluded that the two forms of infidelity seemed distinct but that the dichotomous form of stimuli used in jealousy research may lead to a consistent sex difference partly because of plausibility. Although we did not address plausibility, we did use continuous measures on a range of individual behaviors and examined how participants viewed each behavior with respect to how much it indicated sexual infidelity and emotional infidelity. Participants felt that some behaviors were not highly indicative of either form of infidelity (e.g., telling dirty jokes or talking about major life goals), whereas some behaviors (e.g., intentionally having a child together) was highly indicative of both forms of infidelity.

Another strength of the current study is the use of response options on a ratio scale. Previous studies utilized continuous measures are arguably ordinal or interval and issues with these measures, including restricted scale ranges have been identified as problematic (Edlund and Sagarin 2009). Weems (2004) recommends using wider scale ranges as this increases scale reliability and decreases the use of the midpoint. Our possible range of participant responses from $0-100$ is far wider than that for most psychological research, including studies of reactions to infidelity.

There are many demographic and individual difference variables not assessed in our sample of U.S. undergraduate students that may affect the patterns found in the current study. For example, religiosity, attachment style (Kruger et al. 2013), or perceived availability of alternative mates (Mattingly et al. 2010) may influence how likely one is to label a specific behavior as indicative of emotional infidelity. Similarly, one's romantic relationship status (and associated level of commitment), sexual experience, or first-hand experience with infidelity may exert influence. Foster and Misra (2013) found those who had been led to believe they had perpetrated an infidelity experienced symptoms of cognitive dissonance such as trivialization. In terms of the present work, we would predict that those who had perpetrated an infidelity would be more likely to provide lower ratings for how well the associated behaviors indicate infidelity and decrease the imagined distress.

Some researchers have argued that having such a range of behaviors qualify as infidelity has inadvertently provided an inconsistent definition of the term (Blow and Hartnett 2005). Although that may be true, the present study has produced new data regarding what specific behaviors people consider to be infidelity, as well as how strongly each behavior is considered both sexual infidelity and emotional infidelity, which may aid in developing a consistent definition. Overall, these results may improve the definitions of sexual infidelity and emotional infidelity, as well as demonstrate that evolutionary theory is a useful framework for understanding perceptions of issues related to romantic relationships. Although we believe we have advanced the understanding of infidelity perceptions, we note there remain several unresolved questions for future research. 


\section{Appendix}

Table 4 Item descriptives by participant sex

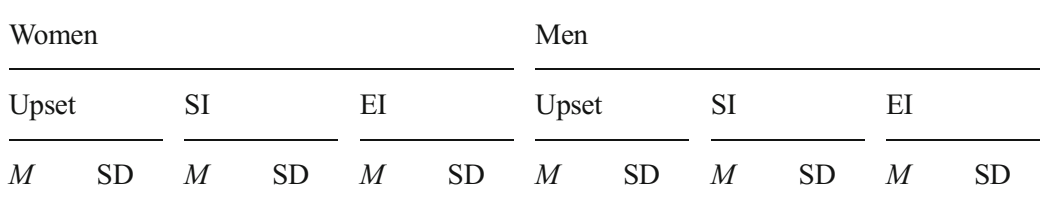

Intentionally having a child together

Penile-vaginal intercourse

Accidentally having a child together

Taking a shower together

Oral sex

Having sex just once

E-mailing or texting erotic pictures of themselves

E-mailing or texting erotic written messages

Kissing on the lips

E-mailing or texting erotic pictures of someone else

Sleeping in the same bed

Watching a pornographic movie together

Going on vacation together

Holding hands

Telling the other person that they are attracted to them

Staying in the same hotel room

Sitting in lap

Telling about sexual fantasies

Flirting with the other person

Accompanying to a strip club

Taking a road trip to another city

Telling about sexual experiences with current partner

Spending lots of time together

Forming a deep emotional bond

Bringing home to meet parents

Calling when upset about their relationship partner

Accompanying to a dance club

Accompanying to a formal event

Giving $\$ 500$

Talking on the phone several times a week

Telling about sexual experiences with ex-partners

Kissing on the cheek

E-mailing or texting several times a week

Going out to dinner

Sharing secrets

Accompanying to a sit-down bar

Hugging for more than 10 seconds

Watching a romantic comedy movie together

Accompanying to a party

Calling when upset about work

Telling about non-sexual experiences with current partner

Asking for advice on important decisions

Asking for advice on her/his current relationship

Telling about non-sexual experiences with ex-partners $\begin{array}{llllllllllll}95.89 & 16.03 & 91.50 & 24.38 & 87.64 & 28.51 & 90.28 & 23.33 & 84.78 & 31.94 & 77.02 & 37.30\end{array}$

$\begin{array}{lllllllllllll}95.86 & 15.70 & 94.93 & 19.51 & 54.71 & 40.85 & 91.52 & 20.75 & 86.48 & 30.24 & 58.13 & 40.65\end{array}$

$\begin{array}{lllllllllllll}95.13 & 17.89 & 94.18 & 18.99 & 58.87 & 40.57 & 91.57 & 21.44 & 86.06 & 27.31 & 55.52 & 40.28\end{array}$

$\begin{array}{llllllllllll}94.99 & 16.01 & 90.80 & 20.33 & 43.06 & 38.71 & 91.35 & 20.25 & 81.66 & 29.06 & 49.12 & 39.45\end{array}$

$\begin{array}{lllllllllllll}94.91 & 17.38 & 94.82 & 18.89 & 40.43 & 38.94 & 91.29 & 21.82 & 87.05 & 27.60 & 50.69 & 39.95\end{array}$

$\begin{array}{lllllllllllll}94.06 & 17.80 & 94.06 & 19.95 & 48.17 & 42.07 & 90.66 & 20.46 & 83.76 & 31.48 & 50.58 & 40.44\end{array}$

$\begin{array}{llllllllllll}93.45 & 16.37 & 87.04 & 23.74 & 45.15 & 40.42 & 89.39 & 20.40 & 77.45 & 32.57 & 54.16 & 38.96\end{array}$

$\begin{array}{llllllllllll}92.55 & 17.89 & 85.21 & 25.30 & 48.90 & 40.29 & 87.37 & 21.71 & 77.18 & 30.12 & 53.60 & 38.80\end{array}$

$\begin{array}{llllllllllll}91.52 & 19.50 & 82.28 & 27.08 & 54.03 & 37.37 & 88.34 & 21.94 & 72.65 & 30.33 & 52.75 & 38.40\end{array}$

$\begin{array}{lllllllllllll}89.90 & 21.59 & 74.19 & 32.12 & 41.89 & 36.99 & 85.09 & 22.62 & 65.93 & 32.24 & 46.18 & 35.52\end{array}$

$\begin{array}{lllllllllllll}87.78 & 22.56 & 73.12 & 29.72 & 51.32 & 37.31 & 86.18 & 23.15 & 68.55 & 33.18 & 52.91 & 38.29\end{array}$

$\begin{array}{lllllllllllll}84.37 & 26.31 & 74.80 & 32.00 & 42.46 & 38.75 & 79.84 & 27.41 & 65.45 & 36.33 & 48.50 & 37.91\end{array}$

$\begin{array}{lllllllllllll}82.33 & 26.20 & 44.81 & 37.98 & 61.45 & 31.31 & 75.70 & 28.22 & 43.89 & 38.05 & 54.51 & 35.38\end{array}$

$\begin{array}{lllllllllllll}81.44 & 27.06 & 48.73 & 34.77 & 63.24 & 32.86 & 74.18 & 27.39 & 46.53 & 34.84 & 56.87 & 33.49\end{array}$

$\begin{array}{lllllllllllll}81.20 & 25.65 & 44.57 & 34.39 & 61.64 & 32.16 & 77.13 & 25.08 & 41.60 & 33.85 & 52.10 & 32.88\end{array}$

$\begin{array}{llllllllllll}78.60 & 29.28 & 59.55 & 36.08 & 48.67 & 36.09 & 73.84 & 29.61 & 55.77 & 37.24 & 49.67 & 36.38\end{array}$

$\begin{array}{lllllllllllll}78.39 & 26.76 & 56.99 & 32.03 & 46.88 & 35.09 & 73.44 & 28.78 & 52.77 & 34.94 & 49.51 & 35.22\end{array}$

$\begin{array}{lllllllllllll}76.56 & 29.89 & 69.42 & 31.69 & 45.90 & 36.56 & 72.48 & 30.19 & 58.81 & 33.23 & 42.75 & 36.24\end{array}$

$\begin{array}{lllllllllllll}75.83 & 28.06 & 52.01 & 33.38 & 56.35 & 33.86 & 74.67 & 26.76 & 48.27 & 34.56 & 51.20 & 34.35\end{array}$

$\begin{array}{lllllllllllll}75.01 & 30.79 & 55.92 & 35.21 & 36.37 & 35.79 & 72.46 & 29.46 & 53.27 & 35.94 & 47.00 & 36.99\end{array}$

$\begin{array}{lllllllllllll}72.24 & 29.78 & 30.23 & 33.17 & 53.32 & 30.59 & 67.74 & 29.68 & 30.36 & 34.49 & 44.06 & 32.56\end{array}$

$\begin{array}{lllllllllllll}69.90 & 31.75 & 33.97 & 35.60 & 54.25 & 35.46 & 68.22 & 30.90 & 41.91 & 37.42 & 54.29 & 34.60\end{array}$

$\begin{array}{lllllllllllll}65.07 & 30.19 & 25.87 & 31.07 & 63.23 & 30.73 & 58.84 & 31.48 & 29.31 & 33.26 & 53.19 & 33.59\end{array}$

$\begin{array}{lllllllllllll}64.69 & 31.83 & 17.40 & 28.50 & 76.10 & 30.07 & 55.40 & 31.31 & 24.19 & 33.10 & 64.09 & 36.03\end{array}$

$\begin{array}{llllllllllll}63.94 & 32.42 & 17.37 & 29.25 & 63.31 & 31.70 & 58.62 & 31.44 & 21.97 & 30.46 & 46.76 & 34.57\end{array}$

$\begin{array}{lllllllllllll}63.83 & 31.73 & 13.90 & 24.25 & 62.89 & 32.79 & 58.75 & 28.97 & 24.05 & 33.59 & 58.38 & 32.57\end{array}$

$\begin{array}{lllllllllllll}63.81 & 32.20 & 39.97 & 32.86 & 32.61 & 29.71 & 63.20 & 31.48 & 41.99 & 34.14 & 36.61 & 31.78\end{array}$

$\begin{array}{lllllllllllll}63.31 & 33.22 & 22.64 & 29.71 & 49.40 & 32.45 & 54.07 & 30.50 & 32.59 & 35.06 & 47.61 & 33.59\end{array}$

$\begin{array}{lllllllllllll}61.34 & 33.59 & 11.56 & 24.01 & 48.00 & 35.81 & 56.58 & 31.01 & 21.06 & 33.03 & 43.02 & 37.54\end{array}$

$\begin{array}{lllllllllllll}61.32 & 32.00 & 19.87 & 28.57 & 57.19 & 33.43 & 57.05 & 30.93 & 27.34 & 32.24 & 45.71 & 33.13\end{array}$

$\begin{array}{lllllllllllll}59.10 & 33.70 & 39.49 & 35.74 & 45.86 & 33.70 & 61.16 & 32.94 & 42.40 & 35.91 & 48.40 & 35.60\end{array}$

$\begin{array}{lllllllllllll}58.50 & 34.94 & 43.50 & 34.25 & 40.60 & 34.88 & 58.20 & 31.21 & 42.85 & 35.30 & 45.49 & 35.11\end{array}$

$\begin{array}{lllllllllllll}56.08 & 33.00 & 18.84 & 28.15 & 53.11 & 34.13 & 54.46 & 32.09 & 25.05 & 31.43 & 44.71 & 33.36\end{array}$

$\begin{array}{llllllllllll}54.63 & 32.00 & 20.47 & 28.62 & 48.65 & 32.92 & 52.35 & 31.14 & 27.54 & 33.16 & 45.74 & 33.93\end{array}$

$\begin{array}{lllllllllllll}53.82 & 33.44 & 15.25 & 25.69 & 62.00 & 33.01 & 51.44 & 31.08 & 24.43 & 32.81 & 51.81 & 32.79\end{array}$

$\begin{array}{llllllllllll}49.86 & 31.77 & 23.63 & 27.63 & 34.28 & 29.07 & 49.89 & 31.52 & 28.07 & 31.86 & 36.67 & 31.81\end{array}$

$\begin{array}{lllllllllllll}49.74 & 32.61 & 33.46 & 30.07 & 43.52 & 31.19 & 50.37 & 32.39 & 33.20 & 31.47 & 42.29 & 31.22\end{array}$

$\begin{array}{llllllllllll}49.55 & 34.40 & 20.44 & 29.34 & 40.15 & 32.85 & 46.70 & 32.35 & 27.82 & 32.99 & 38.24 & 34.22\end{array}$

$\begin{array}{lllllllllllll}49.05 & 33.28 & 22.42 & 28.14 & 35.52 & 32.73 & 49.27 & 30.45 & 30.21 & 33.26 & 40.10 & 33.69\end{array}$

$\begin{array}{lllllllllllll}44.06 & 33.36 & 10.99 & 22.30 & 48.54 & 35.02 & 41.69 & 30.23 & 19.41 & 30.04 & 43.35 & 35.25\end{array}$

$\begin{array}{lllllllllllll}43.82 & 36.45 & 13.73 & 25.75 & 42.41 & 37.02 & 41.36 & 30.67 & 23.10 & 34.12 & 44.82 & 35.97\end{array}$

$\begin{array}{lllllllllllll}43.70 & 31.47 & 8.16 & 18.82 & 50.75 & 35.11 & 37.21 & 29.46 & 17.67 & 29.70 & 41.15 & 36.14\end{array}$

$\begin{array}{llllllllllll}41.25 & 32.51 & 10.11 & 21.42 & 45.22 & 35.23 & 40.95 & 31.68 & 15.63 & 28.25 & 41.13 & 34.13\end{array}$

$\begin{array}{lllllllllllll}41.14 & 32.27 & 13.53 & 24.73 & 42.21 & 35.32 & 40.85 & 30.42 & 22.41 & 32.61 & 42.16 & 35.44\end{array}$ 
Table 4 (continued)

\begin{tabular}{|c|c|c|c|c|c|c|c|c|c|c|c|c|}
\hline & \multicolumn{6}{|c|}{ Women } & \multicolumn{6}{|l|}{ Men } \\
\hline & \multicolumn{2}{|l|}{ Upset } & \multicolumn{2}{|l|}{ SI } & \multicolumn{2}{|l|}{ EI } & \multicolumn{2}{|l|}{ Upset } & \multicolumn{2}{|l|}{ SI } & \multicolumn{2}{|l|}{ EI } \\
\hline & $M$ & $\mathrm{SD}$ & $M$ & SD & $M$ & SD & $M$ & SD & $M$ & SD & $M$ & SD \\
\hline Going shopping together & 38.17 & 30.09 & 7.73 & 19.54 & 34.03 & 33.71 & 34.31 & 29.28 & 11.42 & 24.28 & 30.01 & 30.19 \\
\hline Talking about what is most important in life & 37.50 & 30.83 & 8.74 & 20.11 & 51.19 & 36.30 & 34.95 & 31.42 & 17.65 & 29.67 & 42.59 & 34.39 \\
\hline Crying in front of the other person & 36.85 & 31.10 & 7.60 & 19.87 & 49.89 & 36.29 & 31.73 & 27.77 & 15.91 & 28.63 & 42.98 & 34.47 \\
\hline Telling dirty jokes & 36.80 & 32.77 & 32.10 & 32.93 & 21.22 & 29.01 & 42.62 & 33.16 & 35.14 & 35.02 & 29.99 & 33.02 \\
\hline Watching a comedy movie together & 35.21 & 33.01 & 11.56 & 23.55 & 27.21 & 32.96 & 35.06 & 30.25 & 20.47 & 32.69 & 34.17 & 37.42 \\
\hline Talking about major life goals & 32.44 & 29.79 & 7.74 & 19.02 & 45.32 & 35.58 & 33.02 & 31.92 & 15.76 & 28.58 & 36.82 & 34.26 \\
\hline
\end{tabular}

Upset $=$ ratings of distress, $\mathrm{SI}=$ ratings of sexual infidelity, $\mathrm{EI}=$ ratings of emotional infidelity

\section{References}

Atkins, D. C., Baucom, D. H., \& Jacobson, N. S. (2001). Understanding infidelity: correlates in a national random sample. Journal of Family Psychology, 15, 735-749. doi:10.1037/0893-3200.15.4.735.

Blow, A. J., \& Hartnett, K. (2005). Infidelity in committed relationships I: a methodological review. Journal of Marital and Family Therapy, $31,183-216$.

Buckle, E., Gallup, G. G., \& Rodd, Z. A. (1995). Marriage as a reproductive contract: patterns of marriage, divorce, and remarriage. Ethology and Sociobiology, 17, 363-377.

Buller, D. J. (2005). Evolutionary psychology: the emperor's new paradigm. Trends in Cognitive Science, 9, 277-283.

Buss, D. M., Larsen, R. J., Westen, D., \& Semmelroth, J. (1992). Sex differences in jealousy: evolution, physiology, and psychology. Psychogical Science, 3(4), 251-255.

Buunk, B. (1980). Extramarital sex in the Netherlands. Alternative Lifestyles, 3, 11-39.

Brase, G. L., Adair, L. A., \& Monk, K. (2014). Explaining sex differences in reactions to relationship infidelities: comparisons of the roles of sex, gender, beliefs, attachment, and sociosexual orientation. Evolutionary Psychology, 12, 73-96.

Clarke, V., Braun, V., \& Wooles, K. (2014). Thou shalt not covet another man? Exploring constructions of same-sex and different-sex infidelity using story completion. Journal of Community and Applied Social Psychology. doi:10.1002/casp.2204.

DeSteno, D. A., \& Salovey, P. (1996). Evolutionary origins of sex differences in jealousy? Questioning the "fitness" of the model. Psychological Science, 7, 367-372.

Dural, S., Cetinkaya, H., Can, S., Kaya, A. G., \& Hünler, O. S. (2014). Examination of sex differences in the responses to heterosexual and homosexual infidelity. Anatolian Journal of Psychiatry, 15(1), 1523. doi:10.5455/apd.39255. Turkish.

Edlund, J. E., \& Sagarin, B. J. (2009). Sex differences in jealousy: Misinterpretation of nonsignificant results as refuting the theory. Personal Relationships, 16, 67-78.

Fenigstein, A., \& Peltz, R. (2002). Distress over the infidelity of a child's spouse: a crucial test of evolutionary and socialization hypotheses. Personal Relationships, 9, 301-312.

Fisher, H. E. (1992). Anatomy of love: the natural history of monogamy, adultery, and divorce. New York, NY: W.W. Norton \& Company.

Fisher, M. L., Rekkas, P., Voracek, M., \& Cox, A. (2008). Sex differences in feelings of guilt arising from infidelity. Evolutionary Psychology, $6,436-446$.
Foster, J. D., \& Misra, T. A. (2013). It did not mean anything (about me): cognitive dissonance theory and the cognitive and affective consequences of romantic infidelity. Journal of Social and Personal Relationships, 30, 835-857. doi:10.1177/ 0265407512472324.

Frederick, D. A., \& Fales, M. R. (2014). Upset over sexual versus emotional infidelity among gay, lesbian, bisexual, and heterosexual adults. Archives of Sexual Behavior. doi:10.1007/s10508-0140409-9.

Geary, D. C. (2005). Evolution of paternal investment. In D. M. Buss (Ed.), The evolutionary psychology handbook (pp. 483-505). Hoboken, NJ: Wiley.

Gray, P. B., \& Garcia, J. R. (2013). Evolution and human sexual behavior. Cambridge, MA: Harvard University Press.

Green, M. C., \& Sabini, J. (2006). Gender, socioeconomic status, age and jealousy: emotional responses to infidelity in a national sample. Emotion, 6, 330-334. doi:10.1037/1528-3542. 6.2.330.

Guitar, A. E., Geher, G., Kruger, D. J., Garcia, J. R., Fisher, M. L., \& Fitzgerald, C. J. (under review). Defining and distinguishing sexual and emotional infidelity.

Harris, C. R., \& Christenfeld, N. (1996). Gender, jealousy, and reason. Psychological Science, 7, 364-366.

Hill, K., \& Hurtado, A. M. (1996). Ache life history: the ecology and demography of a foraging people. New York: Aldine.

Jankowiak, W. R., Nell, M. D., \& Buckmaster, A. (2002). Managing infidelity: a cross-cultural perspective. Ethnology, 41, 85-101.

Kostic, B., \& Yadon, C. A. (2014). Infidelity and kin selection: does cheating seem as bad when it's "all in the family"? Evolutionary Psychology, 12(4), 687-705.

Kruger, D. J., Fisher, M. L., Edelstein, R. S., Chopik, W. J., Fitzgerald, C., $\&$ Strout, S. L. (2013). Was that cheating? Perceptions vary by sex, attachment anxiety, and behavior. Evolutionary Psychology, 11, $159-171$.

Maner, J. K., Miller, S. L., Coyle, J. M., \& Kaschak, M. P. (2014). Confronting intrasexual rivals: 2D:4D digit ratio predicts behavioral and endocrinological responses to infidelity threat. Social Psychological and Personality Science, 5, 119128.

Mattingly, B. A., Wilson, K., Clark, E. M., Bequette, A. W., \& Weidler, D. J. (2010). Foggy faithfulness: relationship quality, religiosity, and the perceptions of dating infidelity scale in an adult sample. Journal of Family Issues, 31, 1465-1480.

Sagarin, B. J., Martina, A. L., Coutinho, S. A., Edlund, J. E., Patel, L., Skowronski, J. J., \& Zengel, B. (2012). Sex differences in jealousy: 
a meta-analytic examination. Evolution and Human Behavior, 33, 595-614.

Tsapelas, I., Fisher, H. E., \& Aron, A. (2010). Infidelity: when, where, why. In W. R. Cupach \& B. H. Spitzberg (Eds.), The dark side of close relationships II (pp. 175-196). New York: Routledge.
Weems, G. H. (2004). Impact of the number of response categories on frequency scales. Research in the Schools, 11, 41-49.

Wiederman, M. W., \& Allgeier, E. R. (1993). Gender differences in sexual jealousy: adaptionist or social learning explanation? Ethology and Sociobiology, 14, 115-140. 